\title{
Effect of psychological skill training as a psychological intervention for a successful rehabilitation of a professional soccer player: single case study
}

\author{
Inae Yoon', Yong-Jin Yoon ${ }^{2, *}$ \\ 'Department of Physical Education, College of Education, Dankook University, Jukjeon, Korea \\ ${ }^{2}$ Department of Sport \& Leisure Studies, College of Sciences in Education, Yonsei University, Seoul, Korea
}

The purpose of this study is developing and applying psychological skill training (PST) program as one of the methods of intervention for psychological rehabilitation in order for a successful recovery of the professional soccer player (K). He is currently on rehabilitation training after an injury, and we tried to see the results of this program. It was designed as a program of 17 sessions including 3 interviews and diagnostic checks (psychological skill questionnaire: PSQ, profiles of mood states: POMS) and 14 sessions of PST (goal setting, anxiety reduction, concentration, confidence). After the application of the program, the levels of anxiety reduction, goal setting, concentration, and confidence were visibly increased, and in POMS, which is an indicator of physical rehabilitation process of $\mathrm{K}$, vigor was increased. Meanwhile negative emotions, such as tension, depression, and fatigue were decreased. This program was developed for $\mathrm{K}$, and therefore it has some difficulties in applying it to other players. However, the significance of this study is that it could serve as a basis on developing programs for other players in the rehabilitation process. In addition, it has also proven that PST can be used as a successful method for psychological rehabilitation intervention.

Keywords: Psychological skill training, Psychological intervention, Successful rehabilitation, Professional soccer player

\section{INTRODUCTION}

During the rehabilitation period, players who had been injured raise various psychological reactions such as concern, loss of identity, loneliness, anxiety, loss of confidence, decline of performance, etc. and spend a very agonizing time due to the psychological rather than physical damages (Manuel et al., 2002). When the rehabilitation process takes a long time, players often lose their sense of purpose on recovering, which makes it difficult for them to concentrate on rehabilitation (DeHeredia et al., 2004). Also, players experience stress and negative emotions such as pain, discomfort, anger, sensitivity, depression (Tracy, 2003), loss of confidence, lack of control over the situation (Lynda et al., 2004), anger, frustration, and helplessness (Johnson and Carrol, 2000).

These negative emotions that players undergo during the reha-

bilitation process are related to their perception on physical recovery and psychological conditions (McDonald and Hardy, 1990; Smith et al., 1990). Those emotions are also an important variable that affects players' recognition, behavior, and rehabilitation outcomes, and therefore is important to study their psychological reactions during the rehabilitation process (Alzate et al., 2004; Shin and Yook, 2005; Tracey, 2003).

Alzate et al. (2004) have distinguished sport rehabilitation, the recovery toward of one's athletic performance to pre-injury status, from physical rehabilitation, the recovery toward the physical level before the injury. They argued that a program that combines both physical and sport rehabilitation must be offered to players for a successful rehabilitation. However, as it is clear on the case above, a true rehabilitation process must consist of not only sport rehabilitation but also psychological rehabilitation. Recently, a need for

\footnotetext{
${ }^{*}$ Corresponding author: Yong-Jin Yoon

Department of Sport \& Leisure Studies, College of Science in Education,

Yonsei University, 50 Yonsei-ro, Seodaemun-gu, Seoul, 120-749, Korea

Tel: +82-2-2123-6196 Fax: +82-31-902-3768, E-mail: yoonyj@yonsei.ac.kr

Received: August 31, 2014 / Accepted: October 15, 2014
}

This is an Open Access article distributed under the terms of the Creative Commons Attribution Non-Commercial License (http://creativecommons.org/licenses/by-nc/3.0/) which permits unrestricted non-commercial use, distribution, and reproduction in any medium, provided the original work is properly cited. 
developing a rehabilitation program with psychotherapy is on the rise as a method of psychological intervention for a player's psychological rehabilitation and also for shorting the process of rehabilitation (Kolt et al., 2004; Shin and Kim, 2005). Granito et al. (1995) have presented a recovery program to enhance performance of injured players that consists of four stages: support, education, personal counseling and evaluation. Petipas et al. (1995) have also suggested four stages of counseling to enhance performance of injured players through rapport forming, educational stage, skill improvement stage, and practice and evaluation stage. Skill improvement stage, which is the third stage among four stages, is to help players to gain new strategies (goal setting, relaxation technique, image training, deep breathing, etc.) while supporting players to improve confidence over abilities to solve problems. Moreover, they stated that letting players set short-term goals to evaluate levels of technique acquisitions and to plan implementation strategies helped the psychological recovery of the injured players. The new strategies mentioned here are the psychological methods used in PST, which are strategies used to help players to achieve the best motor performance (Choi et al., 2014; Kim and Jung, 2014; Shon, 2012) by controlling the players' psychological condition (positive self-awareness, coping stress, anxiety reduction, arousal control, confidence improvement, self-esteem improvement) in the recent field of applied psychology for sports. However, PST has been applied mostly to players who perform normally and rarely to those in the rehabilitation process. Therefore, I believe it is necessary to apply the PST method to the players in the rehabilitation process to verify its effectiveness.

Also, it is more useful to take approaches individually rather than offering a program as a group because players in the rehabilitation process have different levels of injuries, injury sites, comeback schedules, levels of anxiety, special circumstances and personal needs. One of these approaches is the single case study, which has proven effective through many researches (Chang et al., 2004; Kim and Chang, 2004; Kim, 2007; Yoon, 2009). Yoon (2009) argues that the effectiveness has proven to be even higher in studies that required various psychological training programs according to the psychological characteristics or requests of the subjects. Therefore, the purpose of this study is to apply a customized PST program to a professional soccer player, who is currently participating in a rehabilitation program and to investigate the effects of the program on the rehabilitation process. Through this result, the rehabilitation trainer will achieve a reference that helps to make a precise judgment on the psychological condition and preparation status for a comeback of the player. It will also serve as an important database for the player to foresee the success of the rehabilitation by receiving psychological and physical rehabilitation together, and also to feel the emotional readiness of his comeback on his own.

\section{MATERIALS AND METHODS}

\section{Participants}

This study had been conducted on a male soccer player, who has been going through rehabilitation treatments and training at a rehabilitation center near Seoul. The participant (hereby known as K) is $24 \mathrm{yr}$ old, and played as a professional soccer player at $\mathrm{J}$ league after college. He was going through a medical examination before signing with a professional soccer team in Korea when he discovered the severity of his injured ankle and as a result, had to postpone his entrance to the soccer team. $\mathrm{K}$ gave up on joining the team and decided to receive surgery, and was in a condition where he needed 6 months of rehabilitation. $\mathrm{K}$, who came to participate in the program through the recommendation of the director at the rehabilitation center, had an anxiety issue that rooted from his desire to finish the rehabilitation process quickly and to find a team to join. It was his third week of rehabilitation training after the surgery when his participation for the program began. His condition did not require crutches, but he could not rest his weight on his right foot. The characteristics of $\mathrm{K}$ are presented in Table 1.

\section{Instruments}

The instruments used in this study that proved the effectiveness of PST as a psychological countermeasure for professional soccer player $(\mathrm{K})$ under rehabilitation training are down below. Each test was given twice-once at the beginning and once at the end of PST application.

\section{1) Psychological skill questionnaire (PSQ)}

The Korean version of PSQ was used to investigate the changes

Table 1. Characteristics of the participant

\begin{tabular}{lccccc}
\hline Sex & Age & Height $(\mathrm{cm})$ & Weight $(\mathrm{kg})$ & Experience (yr) & Rehabilitation period \\
\hline Male & 24 & 187 & 80 & 16 & $\begin{array}{c}\text { Reconstruction of lateral ankle ligament on right } \\
\text { foot, microfracture, bone fragment removal }\end{array}$ \\
\hline
\end{tabular}


of K's performance strategy. This questionnaire consisted of 7-sub components: confidence (4 questions), concentration (4 questions), goal setting (4 questions), teamwork (4 questions), imagery (4 questions), willpower (4 questions), and anxiety control (4 questions). Cronbach' $\alpha$ is .071-.082 (Yoo and Huh, 2002).

\section{2) Profiles of mood states (POMS)}

POMS was used to predict the physical recovery of $\mathrm{K}$. It measured the average emotional state for a recent week. Tracey (2003) suggested that the emotional factors on the injury changes according to the recovery period, and that emotion affects physical recovery. Shin and Yook (2005) also argued that changes in emotional conditions are relevant to recovery.

This questionnaire consisted of tension (tension-anxiety: 9), depression (depression-dejection: 15), anger (anger-hostility: 12), vigor (vigor-activity: 8), fatigue (fatigue-inertia: 7), confusion (confusion-bewilderment: 7), and is composed of Likert type scale of 0-4 (0 point: not at all-4 point: extremely). 7 questions out of 65 questions that do not correspond to the six sub-components were not considered.

\section{3) Interview}

There were a total of 17 interview sessions of $40 \mathrm{~min}$ each, and the interviews took place at the counseling room inside the rehabilitation center, mostly during the mornings to fit K's rehabilitation training schedule. All sessions were recorded with the consent of the player, and the recordings were transcribed for analysis.

\section{Procedure}

The overall process of this study was classified to PST program stage, preliminary stage, and follow-up stage: the in-depth interviews were utilized throughout the whole process. The study sessions were conducted every week from March 5th, 2014 to July 30th, 2014, and there were a total of 17 sessions. The study covers the psychological training period in rehabilitation training schedule with an agreement between the researcher and the rehabilitation team. However, only three sessions were conducted every month due to the reoperation and clinical treatments, and the remaining sessions were substituted with a phone call.

The program was composed to increase goal setting, anxiety control, and attention skill, traits which were indicated on low in the PSQ result at the intake interview. However, with K's request, confidence enhancement was also added due to a two week delay of his comeback.

In-depth interviews based on congruence, unconditional positive regard, and empathy drew on Person-Centered counseling by Rogers (1957) that offers psychological stability and comfort to the injured player at the beginning stages of the rehabilitation process. Most of the conversations were about personal concerns of $\mathrm{K}$, difficulties in rehabilitation process, and the effects and difficulties of PST program. The PST program designed for $\mathrm{K}$ is presented in Table 2.

Table 2. PST program

\begin{tabular}{llll}
\hline Session & Major training content & Significances and tests conducted & Material \\
\hline 1 & Rapport Formation & Interview of player K (To look into his thinking through brain structure) & Brain structure exercise paper \\
2 & Questionnaire & PSQ, POMS & Questionnaires \\
3 & Orientation & results feedback, PST development & PPT \\
$4-6$ & Goal setting training & Lecture on the concept of goal setting and its effect & Paper \\
& & Brain storm & LPT \\
& & Lecture on the concept of anxiety control and its effect & Video \\
$7-9$ & Anxiety control & Abdominal breathing & PPT \\
& & Meditation breathing & Grid board \\
& & Gradual muscle relaxation training & PPT \\
$10-12$ & Attention concentration training & Lecture on the concept of attention concentration and its effectiveness & Red rubber band \\
& & Grid board training & Affirmation card \\
$13-15$ & Confidence training & Hearing concentration training & Questionnaire
\end{tabular}




\section{1) Goal setting}

$\mathrm{K}$ was given time to think about his present and future while looking back on himself through brain storm activities before goal setting. Goals were divided into general goals and rehabilitation goals, and based on the results, we, together with $\mathrm{K}$, set long-term goal (a year), middle-term goal (6 month) and short-term goal (a week), and player K kept a goal accomplishment log to confirm and practice his goals.

\section{2) Anxiety control}

$\mathrm{K}$ was very anxious thinking that if his rehabilitation takes long, he will not be able to find a team, and therefore will have to retire. Also, he insisted that he could not sleep very well for no apparent reason, and felt anxious about the fact that he cannot play soccer at the moment. Therefore, meditations and abdominal breathing were adopted into his training to control the anxiety he felt from time to time. The gradual muscle relaxation methods, which can also be helpful for him when he is back in the field after rehabilitation, were added to his training. These trainings were done before bedtime to help sleep. Methods of meditation, abdominal breathing and gradual muscle relaxation were made into a video for $\mathrm{K}$ to easily watch and focus.

\section{3) Attention concentration}

Concentration is one of the most important psychological skills for players in the field, and it is also important in the rehabilitation process. Players under long-term rehabilitation tend to lose concentration while repeating same work-out sessions every day, and end up working out perfunctorily while chatting with people around. Therefore, the importance of concentration was promoted during interview sessions. During rehabilitation trainings, concentration on muscle movements was emphasized through an exercise to find numbers (1-50) on a grid board. $\mathrm{K}$ also repeated focusing on certain sound among various sounds and then listening to all the other sounds with eyes closed as a part of his concentration training.

\section{4) Confidence}

Confidence was a skill $\mathrm{K}$ wanted himself. He said coach told him that his concentration is weak when he was playing on $\mathrm{J}$ league. Also, K's confidence dropped when he faced many difficult situations (language issues, losing entry opportunities, difficulties from different performance style, etc.) at J league. He also experienced shame when his transfer from $\mathrm{J}$ league to $\mathrm{K}$ league was viewed as a failure personally. Therefore, he was to come up with a statement of self-affirmation and to repeat it every morning and evening.

\section{Data analysis}

Data analysis was done through two methods. First, the results of K's PSQ and POMS were averaged and compared to before and after the training. Second, data achieved from in-depth interviews were recorded and utilized through the transcription process.

Throughout the whole study, triangulation was utilized to secure validity and credibility of the study in the process of construction and proving the effectiveness of PST program.

\section{RESULTS}

\section{Results of PST}

The changes of performance indicated through PSQ and POMS were investigated as pre-program and post-program to prove the effectiveness of PST program for $\mathrm{K}$.

According to K's PSQ results, there were improvements in anxiety reduction, willpower, team work, goal setting, concentration, and confidence after the application of the program. Improvements in anxiety reduction, goal setting, concentration, and confidence, which were major factors of K's psychological training, were clearly visible (Figure 1).

In POMS, which is closely related to K's physical rehabilitation, negative emotions, such as tension were lowered from 2.67 to 2.55 , depression from 2 to 1.73 , and fatigue from 2.71 to 2.28 . Also, vigor was increased from 3.5 to 4 , and anger was increased in a small number from 1.94 to 2.12 (Figure 2).

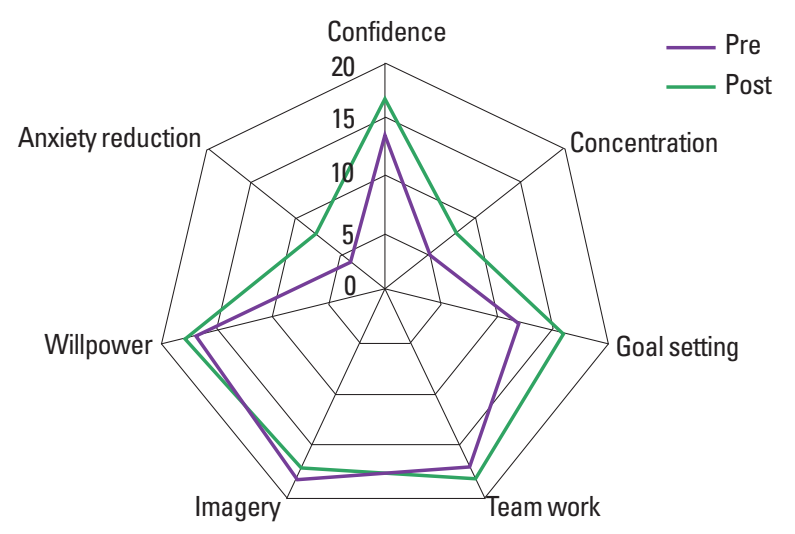

Fig. 1. Results of psychological skills questionnaire. 


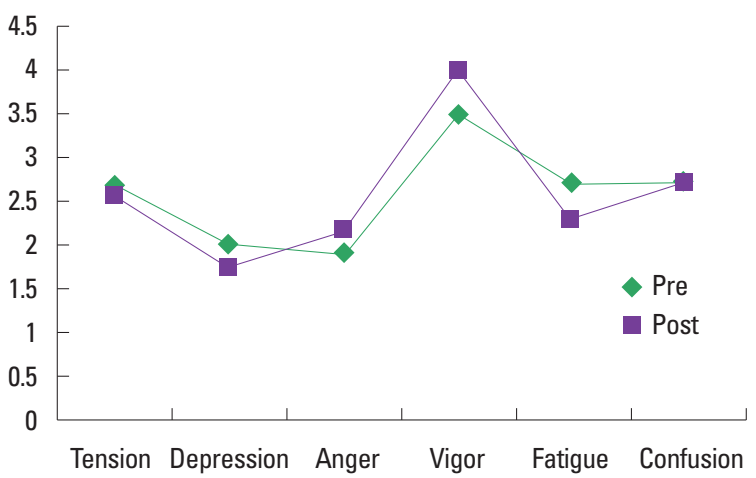

Fig. 2. Results of POMS.

\section{Results of interview}

\section{1) Pre stage}

At the 'to look into K's thinking through brain structure' during rapport formation, $\mathrm{K}$ was thinking the most about the team rather than his rehabilitation. The next of his thought was about soccer and rehabilitation, and the third was about stress and concerns for his future, and going to a graduate school. As a result, it seemed as if he was anxious about not belonging to a team at the moment and also about his recovery. He behaved as if he was focusing more on what other people think of him rather than what he thought of himself. $\mathrm{K}$ said that his nervousness before matches was to the point where it disrupted his performance, and that instructors said his concentration was weak. He was always smiling and used the expression that "everything is fine", which might seem as if he is accepting the situation, but looked as if he had given up rather than showing acceptance. He also talked about difficulties of goal setting.

"I feel urgent but I try to keep composed. I will just... be relaxed. There is nothing else I can do. If I try to do something in haste now it might get worse... my injury could get worse. So..."

"When I started my rehabilitation, I was going to study Japanese and take an exam for a license. I had a plan, but it didn't work out well... I think I'm wasting my time doing nothing"

"I don't really like challenges... I don't take risks. I do regret. I regret at first thinking why did do that? But then I think, what can I do now? That's more comforting."

\section{2) Post stage}

There were times when $\mathrm{K}$ was not enthusiastic about his rehabilitation trainings, especially when he felt pain on his injury site controlling which made him anxious for fear it might get worse. However, he coped well and started controlling himself through by psychological skills he achieved from the researchers and through interviews. As a result, reduced anxiety, aggressive response to his goals, and positive attitudes were verified and increased vigor and confidence.

"I sleep quite well these days. I think meditation helped a lot. When I do that before I fall asleep at night... actually I fall asleep while I'm in the middle. One moment I was breathing, and I open my eyes and it's the morning. Is it okay? I feel good from a good night's sleep."

"I sit down to memorize English vocabulary and practice muscle relaxation as I planned after dinner, even though I feel tired. I do feel tired from all the training when I get home after dinner... But I feel great afterwards. It feels like I really am doing something... I can't play soccer because I'm injured but at least I'm doing something for my future."

"It does get boring while I'm training. It's the same routine every day. There are some fun things once in a while but... I used to think that I want this to be over soon. But now, I concentrate on my muscle, thinking, it will be okay. I will recover, as you told me to, and I really feel that it is getting better and that time goes by quickly."

\section{DISCUSSION}

The purpose of this study is to suggest the process, contents and methods of PST as a countermeasure that helps psychological rehabilitation, which is required for a successful rehabilitation process of professional soccer players, and to prove its effectiveness. The significance of this study is to offer tangible database as a countermeasure for psychological rehabilitation for other players under rehabilitation process.

Players in the process of sports rehabilitation all show different levels of injury, injury sites, recovering speeds, and psychological conditions. At times, some of the players have to make a comeback before the rehabilitation process is completed due to the requests of their coaches. Therefore, interviews and the PST program were composed considering the psychological characteristics and personal needs of the participants through the subject design in order to achieve the goal of this study.

According to the overall analysis of $\mathrm{K}$ before applying to the program, he was missing goals, had doubts on his recovery, felt anxious about his comeback, and lacked concentration and confidence. Therefore, the program was composed to help him make a comeback after completing rehabilitation successfully by enhancing a clear goal, giving assurance on his recovery and focusing on concentration and confidence during training. 
Discussions over the results through the goals and methods of this study are:

First, in the PSQ that measured seven different psychological skills, the three skills that were not part of the participant's PST program (willpower, imagery, team work) did not show much difference while the four psychological skills-goal setting, anxiety reduction, concentration, and confidence- showed much difference.

The direction and intensity of motivation for participation is one of the major factors that decide the success and result of PST. Even though the psychological skill program is well-planned and useful, if the participant is not confident about the program and lacks aggressiveness in terms of practice, then the training becomes useless and there will not be much of a result (Yoon, 2009). Therefore, the participant was encouraged to become actively involved through voluntary participation and acceptance of participant's opinion in composing of PST program. Also, there were lectures at the beginning of each psychological skill to strengthen involvement.

Goal setting was divided into rehabilitation goals and general goals, and the participant said the rehabilitation goals helped him to focus on rehabilitation and to finish its long process. Also, general goals allowed $\mathrm{K}$, who was anxious about his future after recovery, to spend time planning and preparing for it. Through this time, he was able to look at his life with a broader perspective and realized that his life would still continue after his career as a soccer player is over, which helped in reducing anxiety and nervousness. Shelbourne and Foulk (1995) argued that players tend to make a comeback before completing their rehabilitation because they feel nervous as time passes, and because they believe that they have recovered completely when they are not. Therefore, setting proper goals for players in rehabilitation can be a solution, like stated in a study conducted by Shin and Yook (2005) that suggested a need for developing a method to confirm participants' levels of commitment to the programs and to encourage motivation. The skills selected for intervention for psychological rehabilitation, which were goal setting, anxiety reduction, concentration and confidence have proven to be effective through interviews with $\mathrm{K}$.

Second, according to the result of POMS, which was used to predict physical recovery of the participant, negative emotions such as tension, depression and fatigue have decreased and vigor, a positive emotion, has increased. This coincides with a finding from another research (Alzte et al., 2004; Shin and Yook. 2005) that stated how negative emotional conditions of players decrease till the intermediate period of their rehabilitation process and then decrease even more at completion. It also coincides with an- other finding which stated that negative emotions are stronger compared to their normal state right after the injury, but lessens as the rehabilitation process continues while positive emotions increase (Quinn and Fallon 1999). However, it does not entirely coincide with a research study that said world-class elite players have iceberg profiles, characterized as stable and moderate emotional conditions of injured players were also said to transform into something similar to iceberg profile as they recover from their injuries (Shin and Yook, 2005). I believe that this is because, $\mathrm{K}$ went through a reoperation after a month and a half from his first surgery during the rehabilitation, and was feeling some pain on his injury site during the re-measurement after the program had come to an end. This caused the participant to become less certain of his recovery, although his doctor said that his recovery was progressing without any troubles, and therefore, his psychological conditions were not entirely recovered. He needed further progressing of the program, but it could not be made due to the fact that he had to make a comeback.

Therefore in the follow-up study; first, it is necessary to execute a program while constantly observing the participant's psychological status from the moment he visits a hospital for an injury until he achieves a perfect psychological recovery after his comeback in order to discover a precise psychological countermeasure. Second, there should be more variety in researches according to age groups, types of operations, rehabilitation periods, levels of injury, and types of sports.

\section{CONFLICT OF INTEREST}

No potential conflict of interest relevant to this article was reported.

\section{REFERENCES}

Alzate R, Rami'rez A, Luis J. The effects of psychological response on recovery of sport injury. Res Sports Med 2004;12:15-31.

Chang DS, Kim BJ, Gu HM, Shin DS. The effect of the concentration routine of a single-case rifle marksman. Korean J Sport Psychol.2004;15: 79-96.

Choi JS, Woo SW, Yook DW. An application and effects of a psychological sills training on rhythmic gymnasts. J Korean Phy Edu Girls Women 2014;28:35-48.

DeHeredia RA, Munnoz AR, Artaza JL. Effect of psychological response on recovery of sport injury. Res Sport Med 2004;12:15-31.

Granito VJ, Hogan JB, Vamum LK. The performance enhancement group 
program: integrating sport psychology and rehabilitation. J Athletic Training 1995;30:328-331.

Johnson L, Carrol D. Coping social support and injury: Changes over time and the effect of level of sports involvement. J Sport Rehabil 2000;9:290-303.

Kim BJ, Chang DS. Designing mental skills training for elite marksmen using competition reflection. Korean J Sport Psychol 2004;15:93-113.

Kim HG, Jung SH. Effect of badminton national team players applying PSTP effectiveness. Korean J Sport 2014;12:7-17.

Kim JW, A case study of the person-centered counseling and the psychological skill training. Korean J Sport 2007;46:101-113.

Kolt GS, Hume PA, Smith MM. Effects of stress management program on injury and stress of competitive gymnasts. Percept Mot Skill 2004; 99: 195-207.

Lynda M, Sean M, Robin E, Mark A, Paul C, Viciki K, Christne P, Doug W. Emotional reaction of varsity athletes to sport-related concussion. J Sport Exerc Psychol 2004; 26:119-135.

Manuel JC, Shilt JS, Curl WW, Smith JA, DuRant RH, Lester L. Coping with sports injuries: An examination of the adolescent athlete. J Adolescent Health 2002;31:391-393.

McDonald SA, Hardy CJ. Affective response patterns of the injured athlete: an exploratory analysis. Sport Psychologist 1990;4:261-274.

Petipas A, Danish S, Murphy S. Caring for injured athletes. Sport Psychol Interven 1995;255-281.

Quinn IM, Fallon BJ. The changes in psychological characteristics and re- actions of elite athletes from injury onset until full recovery. J Appl Sport Psychol 1999;11:210-229.

Rogers CR. The necessary and sufficient conditions of therapeutic personality change. J Psychotherapy 1957;21:95-103.

Shelbourne KD, Foulk DA. Timing of surgery in acute anterior cruciate ligament tears on the return of quadriceps muscle strength after reconstruction using an autogenous patellar tendon graft. Am J Sports Med 1995;23:686-689.

Shin JT, Kim JS. The effects of stress management training on psychology of injured athletes. Korean J Sport Psychol 2005;16:71-87.

Shin JT, Yook DW. The effects of emotional-cognitive psychology factor and rehabilitation adherence on recovery of sport injury. Korean J Sport 2005;44:249-259.

Shon JH. The effect of psychological skills training for men's ssireum player. J Coaching Develop 2012;14:56-64.

Smith AM, Scott SG, O,Fallon WM, Young ML. Emotional responses of athletes to injury. Mayo Clin Proceedings 1990;65:38-50.

Tracey J. The emotional response to the injury and rehabilitation process. J Appl Sport Psychol 2003;15:279-293.

Yoo J, Huh J. Development and validation of the psychological skill questionnaire in sport. Korean J Sport 2002;41:41-50.

Yoon DH. The effects of counseling and psychological skills training on junior golfer's psychological skills and performance. Korean J Sport Psychol 2009;20:133-154. 